\title{
Effect of heat on tensile properties of thin pure titanium foils
}

\author{
Qiu Zheng*, Tetsuhide Shimizu, and Ming Yang \\ Graduate School of System Design, Tokyo Metropolitan University, Hino City, 191-0065 Tokyo, Japan
}

Received 6 January 2015 / Accepted 20 February 2015

\begin{abstract}
The occurrence of size effects in microforming process may result in nonhomogeneous material characteristics. Heat assisted microforming is an effective approach to reduce the influence of size effects. To improve the heating rate, resistance heating method is introduced to the microforming process. To investigate the size effect of heat on material deformation for thin foils in microforming, uniaxial tensile tests were performed for the foils with different grain sizes at different temperatures by tensile testing system incorporating with resistance heating method. The results show that the reduction of the stress at elevated temperatures compared to room temperature is higher for the foils with larger grain size than that for the foils with smaller grain size. The fracture strain decreases with increasing temperature when the temperature is below $300{ }^{\circ} \mathrm{C}$, and then increases as the temperature increases when the temperature is above $300{ }^{\circ} \mathrm{C}$. In addition, the work hardening behavior of the material is independent of the grain size. As temperature increases, the work hardening increases.
\end{abstract}

Key words: Microforming, Elevated temperature, Pure titanium foils, Grain size, Tensile properties

\section{Introduction}

Microforming has been received much attention in the recent decades due to the wide use of microparts in electronics and biomedical devices. However, the occurrence of size effect [1] in microforming may result in nonhomogeneous material flow and the scattering of the process parameters. One possibility to obtain homogenous material flow is to perform the process at elevated temperatures [2]. To improve the heating rate, resistance-heating-assisted microforming systems were developed by the authors $[3,4]$. These systems have the advantages on improving material formability and reducing forming load with small amount of energy. By using these systems, different kinds of microforming processes, such as micro deep drawing and micro bending were conducted at elevated temperatures. However, the design of resistance-heatingassisted microforming process is still with difficulty since the size effect of heat on material deformation for metal foils in microforming is not clarified clearly yet.

In this study, to investigate the size effect of heat on material deformation in micro sheet forming, uniaxial tensile tests are conducted for thin foils with different grain sizes at different temperatures by resistance heating method. The effect of

*Corresponding author: zheng-qiu@hotmail.com heat on the tensile properties for the foils with different grain sizes is discussed.

\section{Experimental procedure}

Pure titanium (Ti) (JIS TR270C-H) with a thickness of $0.05 \mathrm{~mm}$ were used in this study due to the widely use of pure $\mathrm{Ti}$ and its alloy in medical applications. The tensile specimens were first cut by machining along rolling direction. As shown in Figure 1, the gauge length of the specimen is $16 \mathrm{~mm}$ while the width of the gauge is $4 \mathrm{~mm}$ according to the standard DIN 50125. Then all specimens were polished to remove major burrs to prevent fractures at undesired locations of the specimen. Finally, the specimens were annealed at an isothermal temperature of $650{ }^{\circ} \mathrm{C}$ under a controlled atmosphere of argon gas. During annealing, the temperature was increased to $650{ }^{\circ} \mathrm{C}$ in $20 \mathrm{~min}$ and kept for $10 \mathrm{~min}, 30 \mathrm{~min}$, and $60 \mathrm{~min}$ to obtain different grain sizes. The average grain size $(d)$ of the annealed specimens is about 14.7, 24.5, and $42.4 \mu \mathrm{m}$, for annealing time of 10,30 , and $60 \mathrm{~min}$, respectively.

Uniaxial tensile tests were performed at temperatures of $25,160,300$, and $450{ }^{\circ} \mathrm{C}$ by using the tensile testing system incorporating resistance heating method [5]. The strain rate is $10^{-3} / \mathrm{s}$. The tensile tests were conducted three times at each condition for the accuracy and repeatability. 


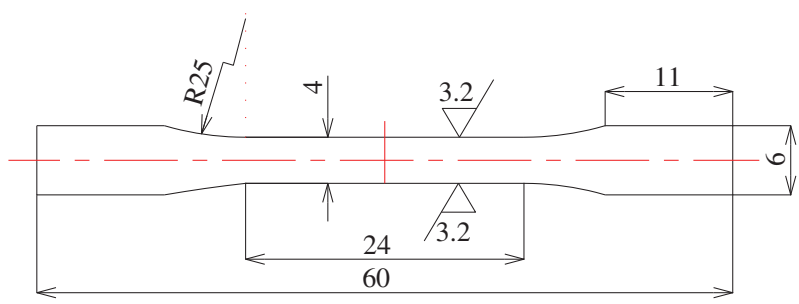

Figure 1. Dimensions of tensile specimen (mm).

\section{Results and discussion}

\subsection{Tensile properties of pure Ti foils with different grain sizes}

\subsubsection{Flow stress}

Figure 2 shows the true stress-true strain curves of thin pure Ti foils with different grain sizes at different temperatures. The flow stress decreases with increasing temperature as expected. Due to the decrease in the strength of the material

(a)

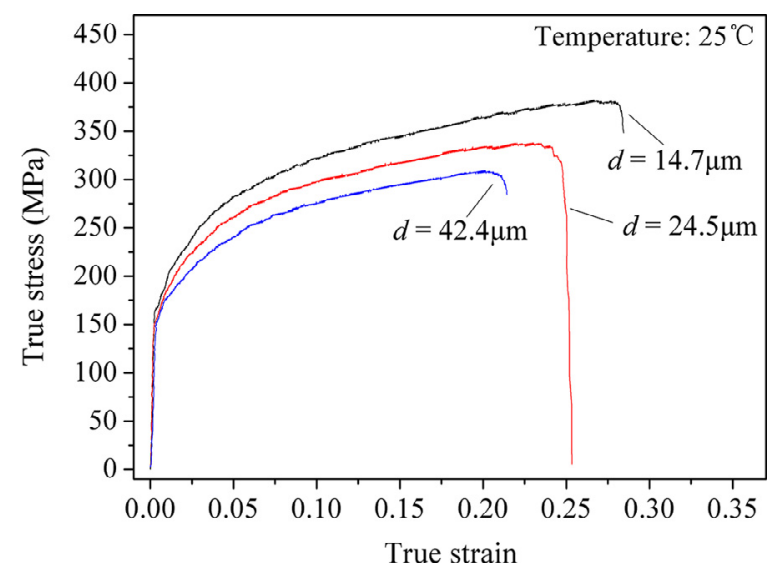

(c)

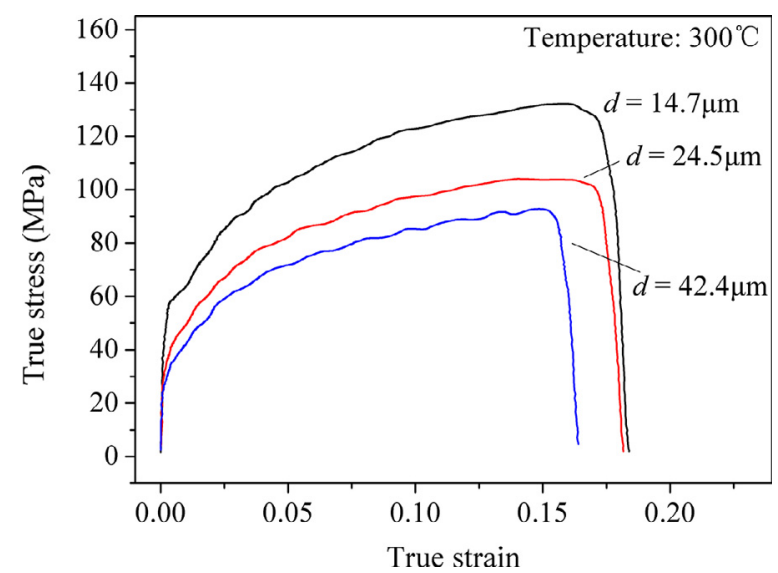

after annealing process, the flow stress decreases with increasing grain size at the same tensile temperature [6]. At the temperature of $300{ }^{\circ} \mathrm{C}$ or lower, the material deformation is mainly consisted of two stages, elastic period and work hardening period. However, at higher temperature of $450{ }^{\circ} \mathrm{C}$, because of the growth of the grains after necking [5], the material exhibits a three-stage deformation pattern including elastic, work hardening and softening period.

Figure 3 shows the yield stress $\sigma_{\mathrm{s}}$ and ultimate tensile stress $\sigma_{\mathrm{b}}$ as a function of temperature. Below $300{ }^{\circ} \mathrm{C}$, the yield stress and ultimate stress decreases rapidly with increasing temperature, while after $300{ }^{\circ} \mathrm{C}$, both of the stress slightly decreases. To observe the effect of heat on the stress for the foils with different grain sizes, the reduction of the yield stress and ultimate tensile stress at elevated temperature is calculated as follows:

$$
\delta_{i}(\%)=\left|\frac{\left(\text { aver } \cdot \sigma_{i}\right)_{j}-\left(\text { aver } \cdot \sigma_{i}\right)_{0}}{\left(\text { aver } \cdot \sigma_{i}\right)_{0}}\right| \times 100 \%,
$$

where $\delta$ is the reduction of the stress at elevated temperature; aver $\cdot \sigma$ is the average stress of three tests under the same tensile condition; $i$ is the stress number, where 1 and 2 (b)

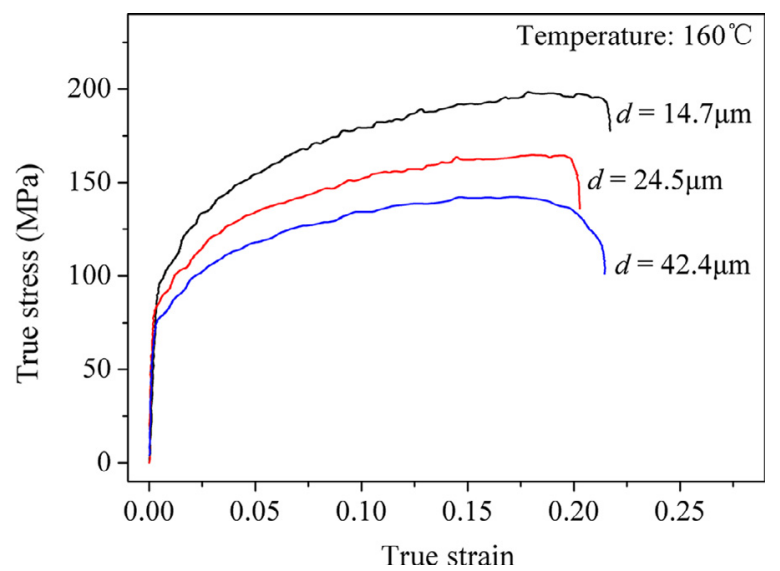

(d)

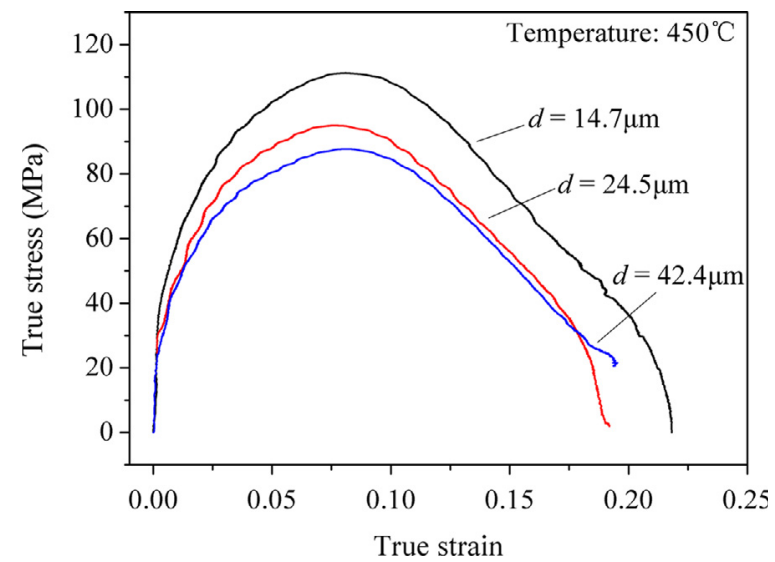

Figure 2. True stress-true strain curves of thin pure Ti foils with different grain sizes at different temperatures of: (a) $25{ }^{\circ} \mathrm{C}$, (b) $160{ }^{\circ} \mathrm{C}$, (c) $300{ }^{\circ} \mathrm{C}$, and (d) $450{ }^{\circ} \mathrm{C}$. 
(a)

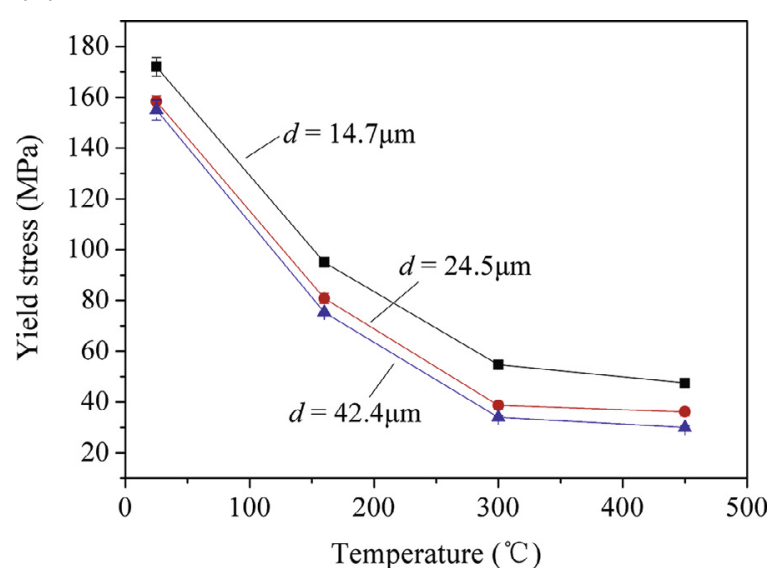

(b)

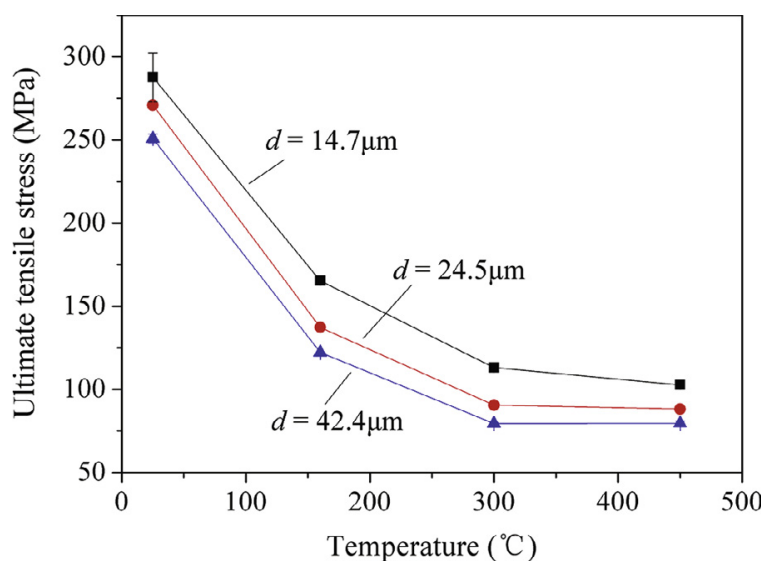

Figure 3. Yield stress and ultimate tensile stress as a function of temperature for the foils with different grain sizes: (a) yield stress $\sigma_{\mathrm{s}}$ and (b) ultimate tensile stress $\sigma_{\mathrm{b}}$.

correspond to the yield stress and ultimate tensile stress, respectively; $j$ is the temperature number, where $0,1,2$, and 3 correspond to $25,160,300$, and $450{ }^{\circ} \mathrm{C}$, respectively.

Figure 4 shows the graph of the calculated reduction of yield stress and ultimate tensile stress. Due to more activated dislocation movements at high temperature and the less grain boundaries of the foils with large grain size, both of the reduction of yield stress and ultimate tensile stress is higher for the foils with larger grain size than that for the foils with smaller grain size.

\subsubsection{Fracture strain}

The effect of heat on the fracture strain is shown in Figure 5. For the foils with different grain sizes, the fracture strain shows the same tendency of decreasing with increasing temperature when the temperature is below $300{ }^{\circ} \mathrm{C}$, and then increasing with increasing temperature when the temperature is above $300^{\circ} \mathrm{C}$. This trend is similar with the study of Huang et al. [7] on pure Ti sheets. At room temperature, because of the better resistance for fracture if the grain size of material (a)

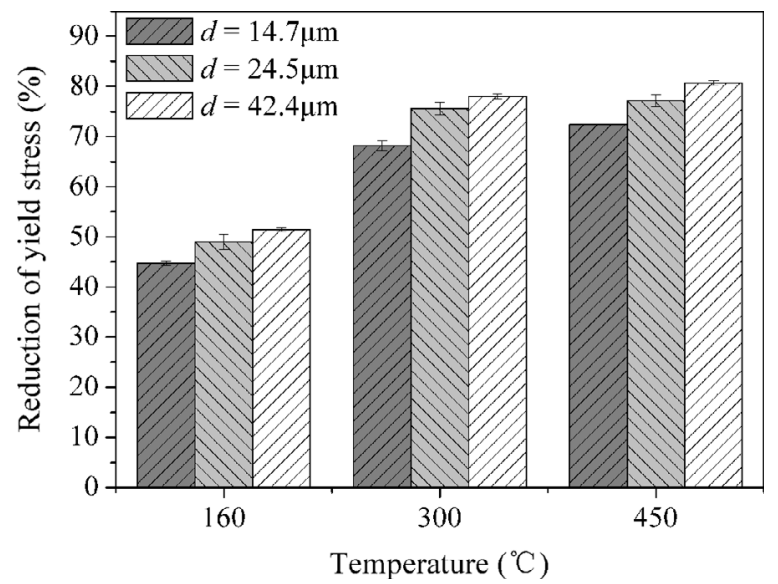

(b)

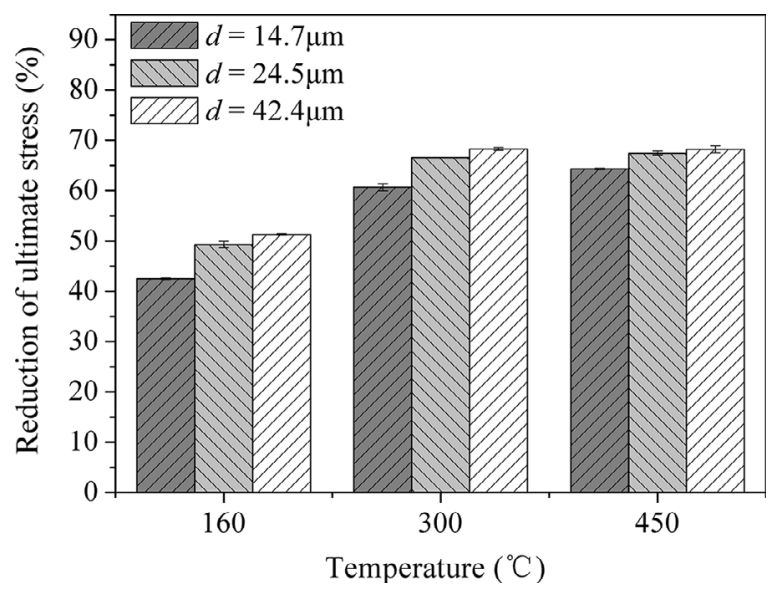

Figure 4. Reduction $\delta(\%)$ of yield stress and ultimate tensile stress at elevated temperatures for the foils with different grain sizes: (a) reduction of yield stress and (b) reduction of ultimate tensile stress.

is smaller, the fracture strain decreases with increasing grain size. While at elevated temperatures, there is no such tendency.

\subsubsection{Work hardening behavior}

The work hardening behavior of the material can be described by the strain hardening exponent $n$. By fitting the true stress-strain curves using Hollomon's equation (see Eq. (2)), $n$ values for the thin foils with different grain sizes at different temperatures can be obtained as shown in Figure 6. For all the foils with different grain sizes, $n$ value shows the same tendency that increases with increasing temperature. In addition, the grain size has no influence on $n$ values.

$$
\sigma=K \varepsilon^{n},
$$

where $\sigma$ is the true stress, $K$ is the strength coefficient, $\varepsilon$ is the true strain, and $n$ is the strain hardening exponent. 


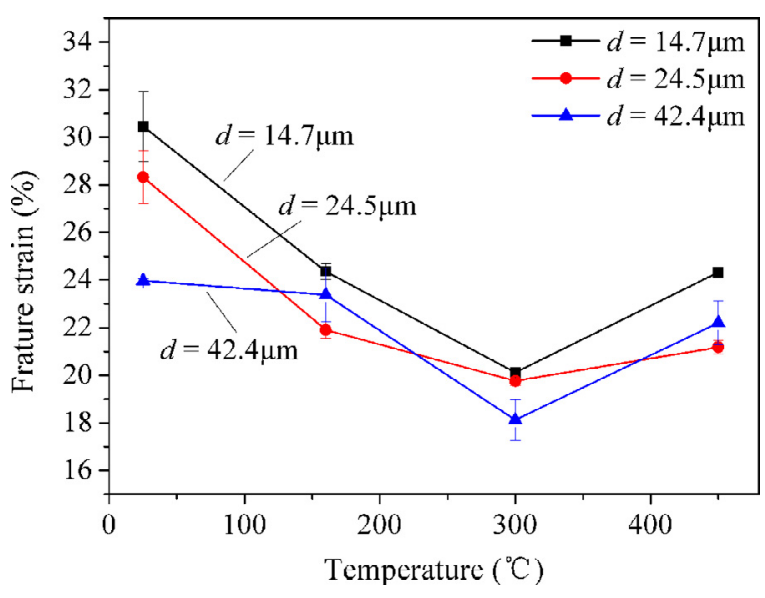

Figure 5. Effect of heat on the fracture strain.

\subsection{Discussion}

In microscale, the material cannot be considered as a homogeneous continuum, but is considered to consist of surface and inner area. Due to the less constrains of the surface, the behavior of the grains in the surface area is assumed to be similar to single crystal behavior, while the behavior of the inner area is described by the behavior of polycrystal $[8,9]$. Therefore, the surface area indicates less flow stress compared with inner area. As the grain size increases, the share of the surface area increases, thus the flow stress decreases. This can be considered as another reason for the tendency that the flow stress decreases with increasing grain size (see Figure 2). At the temperature of $450{ }^{\circ} \mathrm{C}$, due to the higher temperature in the necking area, the grains begin to grow [5]. This results in the softening of the material as shown in Figure 2d.

At elevated temperatures, the flow stress of the material decreases. In microscale, due to the less grain boundaries and less restriction of the surface area, the flow stress of the surface area decreases more than the inner area as the temperature increases. This phenomenon can be considered as the reduction of the flow stress at the inner area is assumed to be the same as the surface, while the thickness of the surface area is assumed to increase with increasing temperature. If the temperature increases infinitely, the deformation behavior of the whole material will be considered as the behavior of single crystal. This can be considered as another reason for the tendency that the reduction of the stress is higher for the foils with larger grain size than that for the foils with smaller grain size (see Figure 4). In the future, the investigation on the constitutive model will be conducted to predict the flow stress by using the explained assumption. Thus, the design of the resistance-heating-assisted microforming process can be achieved.

In addition, the density of deformation twins decreases with increasing temperature [7]. This results in the reduction of strain hardening rate. Thus, the fracture strain decreases due to the local deformation caused by a smaller strain hardening rate at lower temperature. At $450{ }^{\circ} \mathrm{C}$, the fracture strain

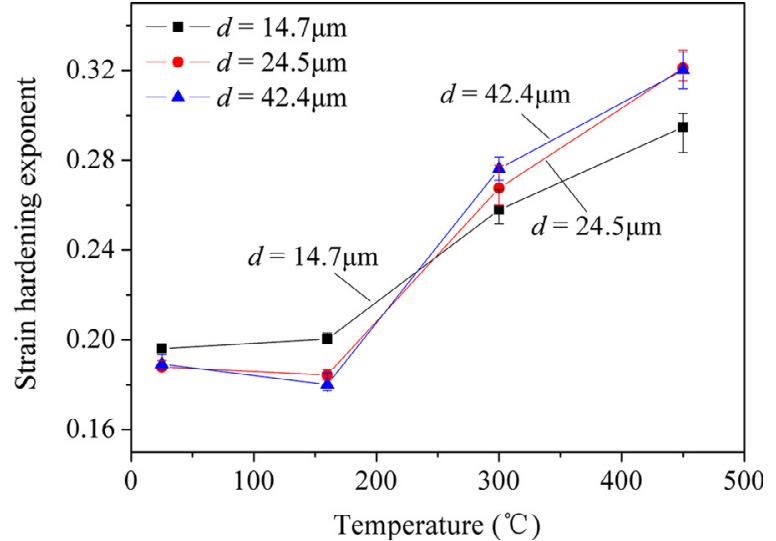

Figure 6. Strain hardening exponent $n$ for the thin foils with different grain sizes at different temperatures.

increases because of the occurrence of the softening behavior. However, as the temperature increases, the material shows more work hardening as shown in Figure 6. Even though the imperfect defects and initial dislocation density decreases after annealing process, more slip systems are activated during the deformation of pure Ti [10]. Therefore, the increase of dislocation density during deformation is one of the reasons for the increasing value of work hardening exponent $(n)$. The occurrence of dynamic strain aging is another reason for the increase in $n$ value. The dynamic strain aging of pure Ti often occurs in the strain rates of $3 \times 10^{-5}-3 \times 10^{-2} / \mathrm{s}$ [11], which increases the strength of the material. Thus, the work hardening behavior increases with increasing temperature.

\section{Conclusions}

In the present work, to investigate the size effect of heat on material deformation in micro sheet forming, uniaxial tensile tests were carried out for thin pure Ti foils with different grain sizes at different temperatures by resistance heating method. It is found that the reduction of the stress at elevated temperatures compared to room temperature is higher for larger grain size foils than that for smaller grain size foils. The fracture strain decreases with increasing temperature when the temperature is below $300{ }^{\circ} \mathrm{C}$, and then increases with increasing temperature when the temperature is above $300{ }^{\circ} \mathrm{C}$. In addition, the work hardening behavior of the material increases with increasing temperature, and is independent of the grain size. In the future, to clarify the influence of grain size on the material deformation for thin foils in resistance-heating-assisted microforming comprehensively, a more detailed study on the strain rate sensitivity will be conducted.

Acknowledgements. The authors would like to express their gratitude to Prof. Ken-ichi Manabe and Tsuyoshi Furushima in Department of Mechanical Engineering, Tokyo Metropolitan University, for their assistance and support on the tensile testing machine. The authors would also like to thank Komatsuseiki Kosakusho. Co., Ltd. Company for their help on the observation of microstructure for the thin foils after annealing. 


\section{References}

1. F. Vollertsen, D. Biermann, H.N. Hansen, et al., Size effects in manufacturing of metallic components, CIRP Annals-Manuf. Technol. 58 (2009) 566-587.

2. E. Egerer, U. Engel, Process characterization and material flow in microforming at elevated temperature, J. Manuf. Process. 6 (2004) 1-6.

3. H. Tanabe, M. Yang, Design and evaluation of heat assisted microforming system, Steel. Res. Int. Special Issues (2011) $1020-1024$.

4. T. Aoyama, T. Shimizu, Q. Zheng, M. Yang, Effect of heating on springback in heat assisted microbending, Adv. Mater. Res. 939 (2014) 409-414.

5. Q. Zheng, T. Shimizu, T. Shiratori, M. Yang, Tensile properties and constitutive model of ultrathin pure titanium foils at elevated temperatures in microforming assisted by resistance heating method, J. Mater. Des. 63 (2014) 389-397.
6. W.F. Smith, J. Hashemi, Foundations of materials science and engineering, Published by McGraw-Hill, Fifth Edition, 2011, pp. $254-267$.

7. W. Huang, X. Zan, X. Nie, et al., Experimental study on the dynamic tensile behavior of a poly-crystal pure titanium at elevated temperatures, Mater. Sci. Eng. A 443 (2007) 33-41.

8. U. Engel, R. Eckstein, Microforming-from basic research to its realization, J. Mater. Process. Technol. 125-126 (2002) 35-44.

9. S. Geißdörfer, U. Engel, M. Geiger, FE-simulation of microforming processes applying a mesoscopic model, Int. J. Mach. Tools Manuf. 46 (2006) 1222-1226.

10. J.M. Liu, S.S. Chou, Study on the microstructure and formability of commercially pure titanium in two-temperature deep drawing, J. Mater. Process. Technol. 95 (1999) 65-70.

11. S. Nemat-Nasser, W.G. Guo, J.Y. Cheng, Mechanical properties and deformation mechanisms of a commercially pure titanium, Acta mater. 47 (1999) 3705-3720.

Cite this article as: Zheng Q, Shimizu T \& Yang M: Effect of heat on tensile properties of thin pure titanium foils. Manufacturing Rev. $2015,2,3$. 